\title{
In Vitro Generation of Adult Rat Olfactory Sensory Neurons and Regulation of Maturation by Coculture with CNS Tissues
}

\author{
Raymond J. Grill and Sarah K. Pixley \\ Department of Cell Biology, Neurobiology and Anatomy, University of Cincinnati College of Medicine, \\ Cincinnati, Ohio 45267-0521
}

\begin{abstract}
Olfactory sensory neurons (OSNs) are continually generated throughout life. Although previous studies have examined neurogenesis in olfactory cell cultures derived from embryonic or newborn rodents, we demonstrate neurogenesis in cell cultures derived from adult rat tissues. Dissociated cells taken from adult rat nasal mucosal tissues (ANM cells) were plated onto a feeder layer of newborn rat cortical glia (astrocytes) in serumfree conditions. Immature OSNs (stained for neuron-specific tubulin, NST) increased in number between 1 and $5 \mathrm{~d}$ in vitro (DIV) and in mass thereafter. Mature OSN (stained for olfactory marker protein, OMP) numbers decreased between 1 and 5 DIV, then increased over 5 DIV values by 12 and 15 DIV. Pulse labeling with $\left[{ }^{3} \mathrm{H}\right]$ thymidine confirmed in vitro neurogenesis. To determine whether the target cells for OSNs, olfactory bulb (OB) neurons, provide trophic support, dissociated newborn rat
\end{abstract}

OB cells were cocultured with ANM cells on glia. This resulted in greater numbers of OMP-positive $(\mathrm{OMP}+)$ neurons after 9 DIV than ANM-alone cultures. This neurotrophic effect was not $\mathrm{OB}$ specific. Addition of newborn rat cerebellar and embryonic rat ventral mesencephalic cells to ANM cells also increased $\mathrm{OMP}+$ neurons, whereas addition of newborn rat cortical cells or controls (purified glia or fibroblasts) did not. Changes in numbers of dopaminergic neurons (stained for tyrosine hydroxylase), present in $\mathrm{OB}$ and VM cultures, did not correlate with $\mathrm{OMP}+$ neuronal increases. Thus, cultures of adult rat OSNs demonstrate neurogenesis, and trophic/maturation support is variably provided by CNS neurons (and not glia).

Key words: olfactory mucosa; neurogenesis; neuronal maturation; rat; nerve growth factors; cell culture; cocultures
Olfactory sensory neurons (OSNs) are continually generated throughout life in mammals (Graziadei and Monti Graziadei, 1978a,b, 1979; Farbman, 1992). The extent of neurogenesis is unique, and understanding the underlying mechanisms could be useful clinically, i.e., by facilitating the use of neuronal stem cells as a potential therapy in the diseased or injured CNS. To study the regulation of olfactory neurogenesis, cell culture systems have been developed previously using either embryonic (Chuah and Farbman, 1983; Calof and Chikaraishi, 1989; Chuah et al., 1991; Farbman and Buchholz, 1992) or newborn (Pixley and Pun, 1990; Ronnett et al., 1991; Trombley and Westbrook, 1991; Pixley, 1992a; Grill and Pixley, 1993) rodent tissues. Here we document that cultures derived from adult olfactory tissues support neurogenesis.

OSN genesis, differentiation, and long-term survival occur when dissociated newborn rat nasal cells are plated on feeder layers of astrocytes (Pixley, 1992a). In vitro neurogenesis was demonstrated by pulse labeling with $\left[{ }^{3} \mathrm{H}\right]$ thymidine. The neurons generated include immature OSNs (Pixley, 1992a), which are immunoreactive for the class III $\beta$-tubulin (neuron-specific tubulin, NST; Lee and Pixley, 1994), and mature OSNs, which are immunoreactive

Received July 11, 1996; revised Jan. 22, 1997; accepted Jan. 31, 1997.

This work was supported in part by National Institute of Deafness and Other Communication Disorders Grant DC00347. We also acknowledge the statistical assistance of David Moore of the University of Cincinnati Institute of Scientific Research.

Correspondence should be addressed to Dr. Sarah K. Pixley, Department of Cell Biology, Neurobiology and Anatomy, University of Cincinnati, College of Medicine, P.O. Box 670521 (231 Bethesda Avenue for courier mail), Cincinnati, OH 45267-0521.

Dr. Grill's present address: Department of Neurosciences, University of California, San Diego, La Jolla, CA 92093-0608.

Copyright (C) 1997 Society for Neuroscience $\quad 0270-6474 / 97 / 173120-08 \$ 05.00 / 0$ for both NST and the olfactory marker protein, OMP, a specific marker of mature OSNs (Farbman and Margolis, 1980; Graziadei et al., 1980; Pixley, 1992a; Lee and Pixley, 1994). The OSNs in these cultures aggregate into tightly packed spheres of NST+ neurons by 15 d in vitro (DIV; Pixley, 1992a; Pixley et al., 1994) that have been termed "micro-noses" because of phenotypic resemblances to the intact epithelium (Pixley et al., 1994).

Similar culture techniques have been used in this study to generate cultures that support survival and generation of adult rat OSNs. The time course of neuronal differentiation in vitro was similar to that seen in newborn rat cultures. These adult OSN cultures were then used to investigate trophic interactions between OSNs and their target cells in the olfactory bulb (OB). Contact between OSN axons and neurons in the OB is not absolutely necessary for maturation of OSNs (ciliogenesis and expression of OMP) in vivo, as seen after bulbectomies (Schwob et al., 1992), in culture (Chuah and Farbman, 1983; Pixley, 1992a), or in transplants to the anterior chamber of the eye (Barber and Jensen, 1988). However, OB-OSN contact may provide trophic support for immature OSNs, preventing premature death and allowing OSNs to live long enough to express OMP (Carr and Farbman, 1992, 1993; Schwob et al., 1992). Olfactory explant culture studies demonstrated that support is specifically provided by bulb tissues and requires physical contact (Chuah and Farbman, 1983; Chuah et al., 1985; Chuah and Au, 1988). Using adult rat dissociated cell cultures, we also demonstrated bulb-derived support of OSNs. In addition, our data suggest that the support is provided by neurons and not glia. In contrast to the explant studies, we demonstrate support of OSNs by cells from some nontarget CNS regions. Thus, dissociated olfactory neuron cell cultures derived from adult rat tissues support neurogenesis and 


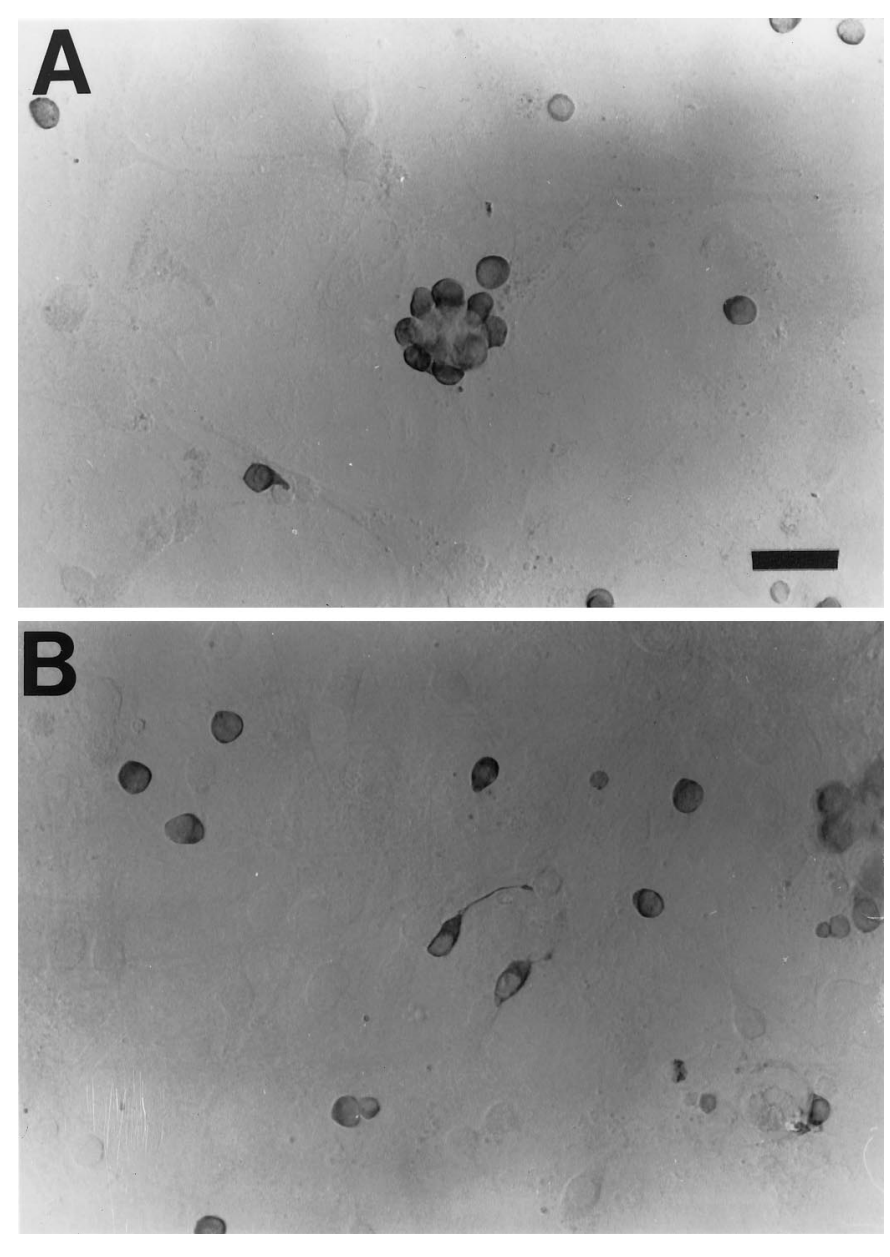

Figure 1. ANM-alone cultures initially contained large numbers of OMP+ OSNs. $A$, At 1 DIV, OMP+ OSNs exhibited a rounded morphology and were often found in various sized multicellular aggregates. The aggregates containing OMP+ OSNs were thought to result from incomplete dissociation of the nasal mucosal tissues and incomplete removal by the sieving step, which involved passage through a $210 \mu \mathrm{m}$ sieve. Scale bar $=30 \mu \mathrm{m} . B, \mathrm{OMP}+\mathrm{OSNs}$ were also found as isolated cells scattered across the glial feeder layer. Some of these OSNs exhibited one or more processes. Whereas growth cone-like structures can often be seen at the tip of some of these processes, we cannot confirm that ciliogenesis occurs in our cultures. OMP + OSNs seemed to rest solely on the glial feeder layer, and not on any exposed glass surface.

can be used to investigate the effects of target-derived growth factors on OSNs.

\section{MATERIALS AND METHODS}

Cocultures. All cocultures were prepared as follows. Cortical glial cells were passaged from stock cultures onto NaOH-cleaned (Pixley, 1992a) glass coverslips (10 $\mathrm{mm}$ diameter rounds, Dynalab, Rochester, NY) at $1.0 \times 10^{5}$ cells $/ \mathrm{cm}^{2}$ in 48 well multiwell plates (Fisher, Cincinnati, $\mathrm{OH}$ ) to establish a feeder layer. After $48 \mathrm{hr}$, the cells selected for coculture (OB, CERE, VM, CORT, OBGLIA, OB2XCX, or FIBRO) were added at $5.0 \times 10^{4}$ cells $/ \mathrm{cm}^{2}$ (see Fig. $1 B$ ). After an additional $48 \mathrm{hr}$, dissociated nasal mucosal cells from adult rats (ANM cells) were added at $5.0 \times 10^{4}$ cells $/ \mathrm{cm}^{2}$.

Cultures of nasal mucosal cells from adult rats. Adult female Sprague Dawley rats (Zivic Miller, Pittsburgh, PA) were given a lethal injection of sodium pentobarbital and decapitated. After discarding the brain and OBs, the cribriform plate, nasal septum, and turbinates were removed and placed in sterile Spinners-MEM (Gibco, Grand Island, NY) with 1.1 $\mathrm{gm} / 1$ sodium bicarbonate, $13 \mathrm{~mm}$ HEPES, $\mathrm{pH}$ 7.3, $1 \mathrm{gm} / 1 \mathrm{BSA}, 2.5 \mathrm{gm} / 1$ nystatin, $2 \mathrm{~mm}$ glutamine, $100 \mathrm{U} / \mathrm{ml}$ penicillin, and $0.1 \mathrm{mg} / \mathrm{ml}$ streptomycin at $37^{\circ} \mathrm{C}$ (this medium is referred to as SMEM). All reagents were from
Sigma (St. Louis, MO) unless otherwise noted. In SMEM, the soft tissue was gently teased away from the underlying cartilage and bone using microdissecting forceps (Roboz, Rockville, MD) and placed into fresh SMEM. After one rinse in SMEM, the tissues were incubated in an enzyme solution (SMEM) containing $1.85 \mathrm{mg} / \mathrm{ml}$ trypsin, $0.7 \mathrm{mg} / \mathrm{ml}$ collagenase (Sigma, catalog \#C-0130) and $4 \mathrm{mg} / \mathrm{ml} \mathrm{BSA} \mathrm{(Sigma,} \mathrm{fraction}$ $\mathrm{V}, 96-99 \%$ albumin) for $1 \mathrm{hr}$ at room temperature on a slowly rocking platform (Hoeffer Scientific, San Francisco, CA). An important detail that aided preparation of adult (but not newborn) rat cultures was the use of a pretested lot of collagenase, as discussed previously (Pixley, 1992c). SMEM with $10 \%$ FCS was then added to inactivate the trypsin, and the tissues were mechanically dissociated by passage through a $5 \mathrm{ml}$ plastic pipet. The resulting cell suspension was passed through a $210 \mu \mathrm{m}$ nylon mesh (Tetko, Elmsford, NY) to remove remaining cartilage and large tissue chunks, centrifuged at $3000 \times g$ for $10 \mathrm{~min}$, and the pellet was resuspended in a serum-free culture growth medium designated DSN1 (Pixley, 1992a, 1996; Grill and Pixley, 1993). Cells were diluted 1:2 in trypan blue and counted on a hemocytometer. Cells were plated in DSN1 at $5.0 \times 10^{4}$ cells $/ \mathrm{cm}^{2}$ on glass coverslips $(10 \mathrm{~mm}$ diameter rounds, Dynalab) pretreated with $0.05 \mathrm{mg} / \mathrm{ml}$ poly-L-lysine (polylysine) or plated with cortical glia (see below).

Cortical glial feeder layer. Glial cultures were prepared from newborn rat (P-0-P-3) cortical tissues as described previously (Pixley, 1992a). Briefly, cortical tissue was taken from newborn rat pups after they were anesthetized with ice and decapitated. Tissue chunks were dissociated in $5 \%$ trypsin in SMEM for $15 \mathrm{~min}$ at room temperature, followed by physical dissociation using a $5 \mathrm{ml}$ plastic pipet. After rinsing, counting, and plating (see above), cells were maintained in a serum-containing medium (Pixley, 1992a) for $7 \mathrm{~d}$ in T-75 tissue culture flasks (Falcon, Franklin Lakes, NJ). At $7 \mathrm{~d}$, the flasks were shaken at $300 \mathrm{rpm}$ in an environmental shaker to remove oligodendrocytes, microglia, and neurons (Levison and McCarthy, 1991). The remaining attached cells were removed with trypsin and EDTA and plated onto $10 \mathrm{~mm}$ glass coverslips as per the first step in ANM-alone cultures. The majority (90-95\%) of these cells were astrocytes as determined by staining with anti-glial fibrillary acidic protein (GFAP; data not shown). The glial feeder layer was maintained in serum-containing medium until the addition of ANM cells.

Newborn rat $O B$ glial or cortical glial cultures. These cultures were prepared at the same time as the newborn rat cortical glial cultures, using the same procedures outlined above.

Newborn rat $O B$ and cerebellar cultures. OBs (10-12 pairs) and cerebella $(6-8)$ were surgically removed from newborn rat pups, enzymatically treated, mechanically dissociated, and plated in serum-containing medium (as for glial cell cultures, see above) to give OB and cerebellar (CERE) cultures.

Embryonic rat ventral mesencephalic and cortical neuronal cultures. One timed-pregnant rat at day 16 of gestation was used per experiment. After a lethal pentobarbital injection to the mother, the embryonic day 16 (E-16) pups were surgically removed, placed on ice, and dissected free of the embryonic sac. Tissues were removed from the mesencephalic flexure (ventral mesencephalic tissues, VM; as per Konig et al., 1989) and from frontal and parietal cortices (cerebral cortical tissues, CORT). Tissues were dissociated as for OB and cerebellar tissues.

Newborn rat belly skin fibroblast cultures. A roughly $15 \times 15 \mathrm{~mm}$ section of belly skin was carefully dissected to exclude muscle and placed into SMEM at room temperature. Tissues were then immersed in a $10 \%$ povidone-iodine solution (Walgreens, Deerfield, Il) for $5 \mathrm{~min}$ to minimize contamination. After rinsing three times with SMEM, the tissues were dissociated in SMEM $+2.5 \mathrm{mg} / \mathrm{ml}$ trypsin $+4 \mathrm{mg} / \mathrm{ml}$ BSA for $4 \mathrm{hr}$ at room temperature. After $4 \mathrm{hr}$, the trypsin was inactivated with SMEM $+10 \%$ FCS. The connective tissues were stripped off the epidermis, then dissociated for an additional hour at room temperature. After adding SMEM with FCS, the tissue was mechanically dissociated by passing through a plastic pipet 10-15 times. Cells were then plated in serumcontaining medium as described above.

Immunocytochemistry and cell counts. At 1, 5, 9, 12, and $15 \mathrm{~d}$, two coverslips per culture condition were fixed in $4 \%$ paraformaldehyde (Electron Microscopy Sciences, Fort Washington, PA) in 0.1 M phosphate buffer, $\mathrm{pH} 7.4(\mathrm{~PB})$, for $15 \mathrm{~min}$ at room temperature. Fixed cells were rinsed in PB three times and incubated for $1 \mathrm{hr}$ in blocking buffer $(0.1 \mathrm{M}$ PBS with $0.2 \%$ Triton $\mathrm{X}-100,0.02 \%$ sodium azide, and $10 \%$ horse serum). Cells were incubated overnight at room temperature in primary antibodies diluted in PBS with $0.2 \%$ Triton and $0.02 \%$ sodium azide. Primary antibodies and dilutions were: neuron-specific tubulin (NST, 
1:5000, mouse monoclonal antibody to the class III isoform of $\beta$-tubulin; Sigma, St. Louis, MO) and olfactory marker protein (OMP, 1:5000, goat polyclonal antibody, generous gift of Dr. F. Margolis, University of Maryland, Baltimore, MD). Cells were incubated in the appropriate biotinylated secondary antibody (1:200; Vector Laboratories, Burlingame, CA) for $2 \mathrm{hr}$, and in the Elite $\mathrm{ABC}$ reagent (avidin $\mathrm{DH}$ biotinylated horseradish peroxidase, 1:400; Vector Laboratories) for $1 \mathrm{hr}$. Antibody binding was visualized with diaminobenzidine $(0.5 \mathrm{mg} / \mathrm{ml}$ in $\mathrm{PB})$. Dilutions and all rinses (3 times between each step) were in PB. After immunostaining, coverslips were mounted on microscope slides with Gelvatol (Harlow and Lane, 1988).

Cells were counted by examining a set pattern of 40 fields per coverslip, at $200 \times$ magnification. Cells from two coverslips per condition per experiment were counted, averaged, and converted to cells $/ \mathrm{cm}^{2}$. Graph points represent the means from at least 3 experiments. Statistical significance for coculture experiments (data set shown in Figs. 3B, 4, and 5, number of experiments per point was 5-7) was tested by a random effects generalized least squares (GLS) regression model, using the Stata software (Stata Corp., College Station, TX). Other data were analyzed by $t$ tests, Mann-Whitney rank sum tests, and one-way ANOVA, using either the SPSS (SPSS Inc., Chicago, IL) or SigmaStat (Jandel Scientific, San Raphael, CA) software.

Pulse labeling with $\left[{ }^{3} H\right]$ thymidine and combined immunocytochemistry and autoradiography. $\left[{ }^{3} \mathrm{H}\right]$ thymidine $(0.03 \mathrm{mCi} / \mathrm{ml})$ was added to $\mathrm{ANM}$ cells on cortical glial feeder layers (ANM-alone) at 5 and 6 DIV, for 24 $\mathrm{hr}$, followed by two rinses with DSN1. Coverslips were fixed at 2 and $3 \mathrm{~d}$ intervals after removal of $\left[{ }^{3} \mathrm{H}\right]$ thymidine and processed for immunocytochemistry using either anti-NST or anti-OMP as primary antibodies. Coverslips were processed for combined immunocytochemistry and autoradiography as described previously (Pixley, 1992a). Neurons born in culture were identified by double labeling; they were immunostained (with NST or OMP) and had silver grains over their nuclei.

\section{RESULTS}

\section{Adult rat nasal mucosal cultures (ANM-alone)}

To study the regenerative capacity of the adult rat olfactory system in vitro, dissociated ANM cells were plated onto either a noncellular substrate or a feeder layer of cortical glia. Plating on glial feeder layers promotes abundant and long-term (greater than 20 DIV) survival, generation, and production of newborn rat olfactory neurons in culture, whereas plating on noncellular substrates supports only limited neuronal survival (no cells survive past 7 DIV; Pixley, 1992a). When dissociated ANM cells were plated on either polylysine or laminin, none survived to $24 \mathrm{hr}$, although cells did attach (data not shown). In contrast, ANM cells plated on cortical glia (ANM-alone cultures) contained large numbers of mature, OMP + OSNs at $24 \mathrm{hr}$ after plating [7757 \pm 777 neurons $/ \mathrm{cm}^{2}$ (mean $\pm \mathrm{SEM}$ )]. Cultures at $24 \mathrm{hr}$ also contained immature OSNs, identified by immunostaining for NST + , although the numbers were fivefold smaller at 1 DIV than mature OSNs $\left[1551 \pm 111\right.$ neurons $/ \mathrm{cm}^{2}$ (mean \pm SEM)]. These numbers demonstrate that, in contrast to the observations in newborn rat cultures, anti-NST did not stain OMP + neurons in these adult rat cultures.

The ratio of OMP + to NST + neurons differed significantly from that observed previously in newborn rat cultures (Pixley, 1992a), primarily because of increases in the OMP + neuron numbers. This is completely consistent with the developmental differences in the intact tissues. The adult epithelium contains several layers of OMP + neuronal cell bodies, but only one of NST+ (Lee and Pixley, 1994) or GAP-43/B-50+ (Verhaagen et al., 1989, 1990) cell bodies, whereas the newborn epithelium contains multiple rows of NST,$+ \mathrm{GAP}-43 / \mathrm{B}-50+$ neurons and 1-2 rows of OMP + neurons (Verhaagen et al., 1989, 1990; Lee and Pixley, 1994).

At 1 DIV, OMP+ OSNs were found as small, multicellular aggregates (Fig. $1 A$ ) or as isolated, individual neurons (Fig. 1B).
Many OMP + OSNs lacked processes (not quantified), whereas others resembled classical OSNs with a round cell body, a small thin process suggestive of an axon, and a short, thick process, suggestive of a dendrite. Olfactory cilia, which would be difficult to distinguish from filipodia on growth cones, were not specifically identified. Immature neurons (NST + ) were bipolar with significantly longer processes. Both types of neurons aggregated (not shown), forming, by 9-15 DIV, some structures resembling the micro-noses seen in newborn rat cultures. However, the size of micro-noses remained significantly smaller than in newborn cultures, and most neurons were found in loose clusters rather than in micro-noses.

\section{OMP+ OSNs disappeared between 1 and 5 DIV}

In vivo, removal of the $\mathrm{OB}$, the target of OSN axons, or severance of OSN axons results in death of the majority of OMP+ OSNs within 5-7 d (Graziadei and Graziadei, 1979; Monti Graziadei and Graziadei, 1979; Costanzo and Graziadei, 1983). The ANM-alone cultures showed a similar rapid loss of OMP + neurons. The numbers of OMP + OSNs observed at 1 DIV (7757 \pm 777$)$ dropped by $98 \%$, to $151 \pm 22$ neurons $/ \mathrm{cm}^{2}$ at 5 DIV (Fig. $2 A$ ). The OMP + OSNs seemed to be dying, because at 5 DIV almost all appeared shriveled and lacked processes (data not shown).

\section{ANM-alone cultures were neurogenic and produced NST+ and OMP+ OSNs}

Whereas the number of mature, OMP + OSNs decreased between 1 and 5 DIV, immature, NST+ OSNs increased by 1.7-fold, from $1551 \pm 111$ on 1 DIV to $2696 \pm 203$ neurons $/ \mathrm{cm}^{2}$ on 5 DIV (Fig. $2 A$ ). Numbers of NST+ OSNs seemed to increase after 5 DIV, but extensive aggregation prevented quantification.

Between 5 and 9 DIV, the number of OMP+ OSNs did not change significantly (Fig. $2 B$ ). However, at $12 \mathrm{DIV}$, the number of OMP + OSNs was significantly higher (approximately threefold) than 5 DIV values. By 15 DIV, there was an approximately fourfold increase in the number of OMP+ OSNs over $5 \mathrm{~d}$ values. Time points after 15 DIV are not included because the culture system became unstable; in many wells the entire cell mat tore away from the underlying glass coverslip (perhaps because of overproliferation of non-neuronal cells). This instability also resulted in increased variability (higher SEMs) of the 15 DIV values (some cultures were beginning to degenerate at 15 DIV).

To determine whether neurogenesis could account for the increases in NST+ (from 1 DIV on) and OMP+ (from 12 DIV on) OSNs in ANM-alone cultures, pulse labeling was done with $\left[{ }^{3} \mathrm{H}\right]$ thymidine for $24 \mathrm{hr}$ starting on either 5 or 6 DIV. NST+, silver grain-labeled OSNs were detected at every subsequent day examined $(9,12$, and 15 DIV; 3-10 d after the pulse; Fig. $3 A)$. OMP + OSNs labeled with silver grains were not detected on 9 DIV ( 3 or $4 \mathrm{~d}$ after the pulse), but they were at 12 and 15 DIV (7-10 d after the pulse) (Fig. 3B). This suggests that OSNs were born in vitro and progressed from an early NST+/OMP - stage to a mature, OMP + stage. This also suggests that maturation of the OSN requires a time period greater than $3 \mathrm{~d}$, which is consistent with pulse-labeling studies in newborn rat cell cultures (Pixley, 1992a).

\section{Cocultures: addition of dissociated newborn rat OB cells promoted increased numbers of OMP+ OSNs in ANM-alone cultures}

Both developmental and experimental data suggest that contact between the OSN axon and the OB is important for OSN maturation (ciliogenesis and OMP expression) and survival (Hinds and 

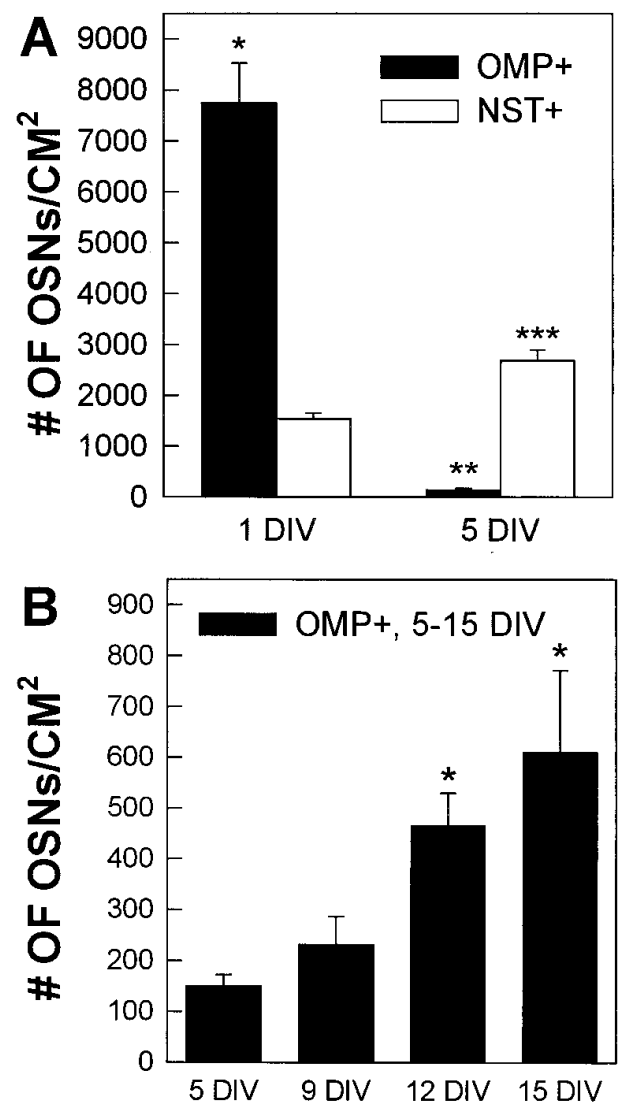

Figure 2. OMP+ OSNs disappeared between 1 and 5 DIV, whereas immature OSNs increased in number. OMP + neurons increased in number after a low at 5 DIV. Error bars represent mean \pm SEM. $A$, At 1 DIV, the numbers of mature OMP $+\mathrm{OSNs} / \mathrm{cm}^{2}$ were fivefold greater than those of immature NST+ OSNs $\left({ }^{*} p<0.01, t\right.$ test). We believe this reflects the normal condition of the adult olfactory epithelium, where the majority of OSNs are OMP+ (Verhaagen et al., 1990). The number of OMP+ OSNs dropped by 52 -fold between 1 and 5 DIV $(* * p<0.05$, Mann-Whitney rank sum test). Immature NST + OSNs, however, increased in numbers by 1.7 -fold between 1 and 5 DIV ( $t$ test, $p<0.01$ ). Thus, by 5 DIV, the ratio of mature to immature OSNs had shifted; numbers of NST+ neurons were 17-fold higher than OMP+ OSNs $\left({ }^{* * *} p<0.05\right.$, Mann-Whitney rank sum test). $B$, Mature OMP $+\mathrm{OSNs} / \mathrm{cm}^{2}$ increased over time in culture. At 12 and $15 \mathrm{DIV}$, but not at $9 \mathrm{DIV}$, the numbers of OMP+ OSNs differed significantly from 5 DIV values (paired samples $t$ test, $p<0.05$ ).

Hinds, 1976; Harding et al., 1977; Costanzo and Graziadei, 1983; reviewed in Farbman, 1992). However, contact is not absolutely necessary because OSN maturation can occur in the absence of contact with any CNS tissue (Chuah and Farbman, 1983; Costanzo, 1984; Barber and Jensen, 1988; Carr and Farbman, 1992; Pixley, 1992a; Schwob et al., 1992; Carr and Farbman, 1993). Data from previous explant culture studies (Chuah and Farbman, 1983; Chuah et al., 1985) and more recent in vivo studies (Carr and Farbman, 1992, 1993; Schwob et al., 1992) support the alternative hypothesis that contact with the OB provides trophic support that prevents early apoptotic death of OSNs, which then allows OSN maturation.

To determine whether contact between dissociated OSNs and dissociated $\mathrm{OB}$ cells in culture could increase the survival and therefore the maturation of OSNs (measured by an increase in number of OMP + cells), dissociated OB cells were plated onto a feeder layer of cortical glia and then ANM cells were added (OB/ANM cocultures).
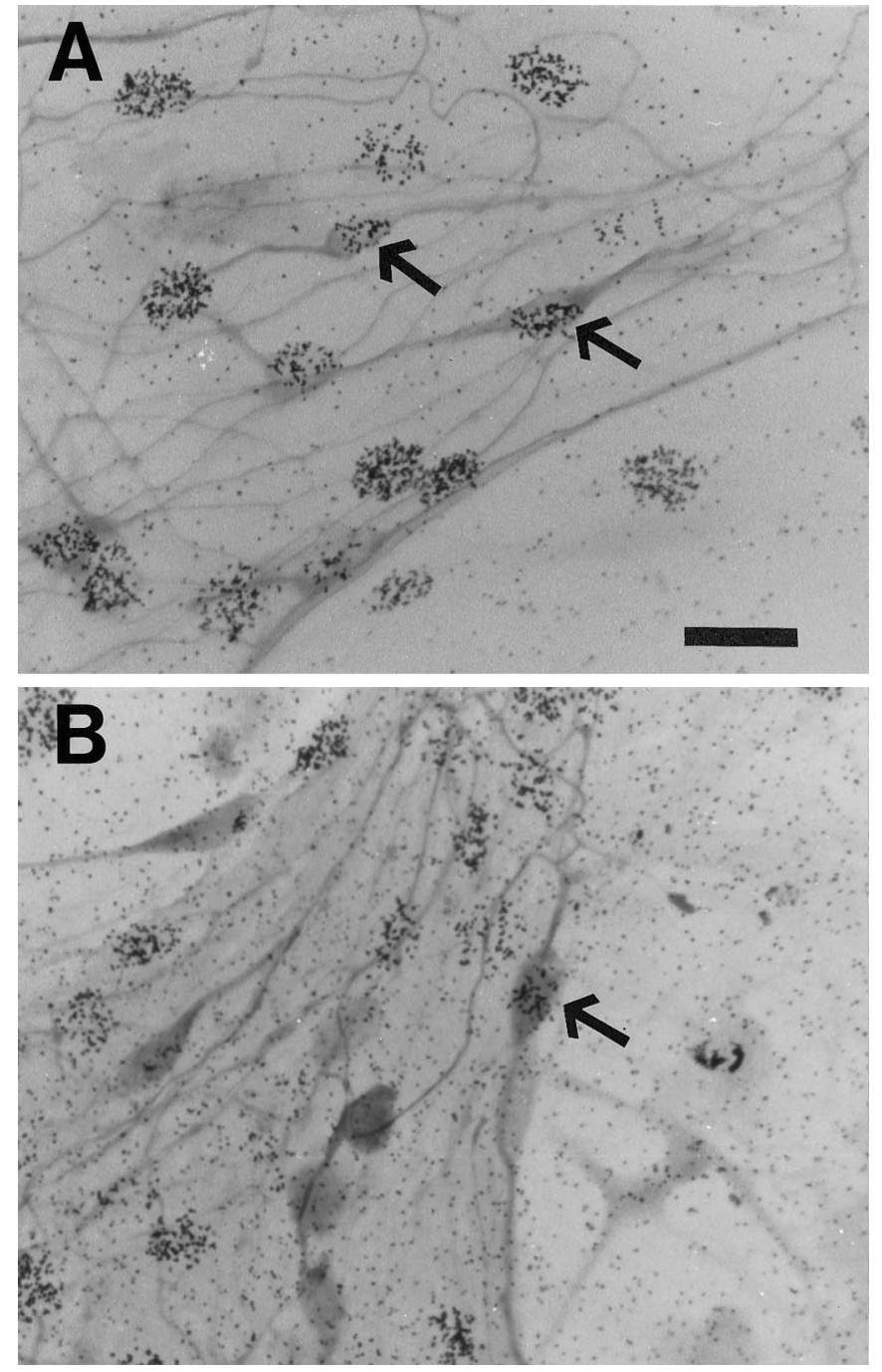

Figure 3. Neurogenesis in adult rat cultures: pulse labeling with $\left[{ }^{3} \mathrm{H}\right]$ thymidine. $A$, The increase in NST + OSNs was a result of neurogenesis. After a $24 \mathrm{hr}$ pulse of $\left[{ }^{3} \mathrm{H}\right]$ thymidine in ANM-alone cultures at $5 \mathrm{DIV}$, NST+ OSNs with silver grain labeling were found at 9 DIV (arrow). B, The increase in OMP+ OSNs was also a result of neurogenesis in vitro. After a $24 \mathrm{hr}$ pulse of $\left[{ }^{3} \mathrm{H}\right]$ thymidine in ANM-alone cultures at $5 \mathrm{DIV}$, OMP+ OSNs with silver grain labeling were not detectable at 9 DIV, but they were at $12 \mathrm{DIV}(C$, arrow $)$. This suggests that newly generated OSNs express NST before expression of OMP. Scale bar, $20 \mu \mathrm{m}$.

At 5 DIV, OB/ANM cocultures did not significantly differ over ANM-alone cultures in numbers of OMP+ OSNs (Fig. 4). However, at 9, 12, and 15 DIV, there were significantly greater numbers of OMP+ OSNs in OB/ANM cocultures compared to ANMalone (2.6-fold, twofold, and twofold, respectively; statistics were done using the entire data set shown in Fig. 5, as described in Materials and Methods). At 15 DIV, there was higher variability in both the ANM alone and OB/ANM alone (see higher SEMs), which we attribute to the instability of the cell mat, which began to pull off in some experiments at around 12 DIV. Control cultures of $\mathrm{OB}$ cells plated on cortical glia (which never showed cell mat instability) did not contain OMP + cells at 1, 5, 9, 12, or 15 DIV (data not shown). No obvious differences in neuronal morphology (either NST + or OMP + neurons) or neuronal aggregation were observed in the cocultures. These data suggest that OB cells provide trophic support for OSNs in dissociated cell cultures just as in explant cultures. 


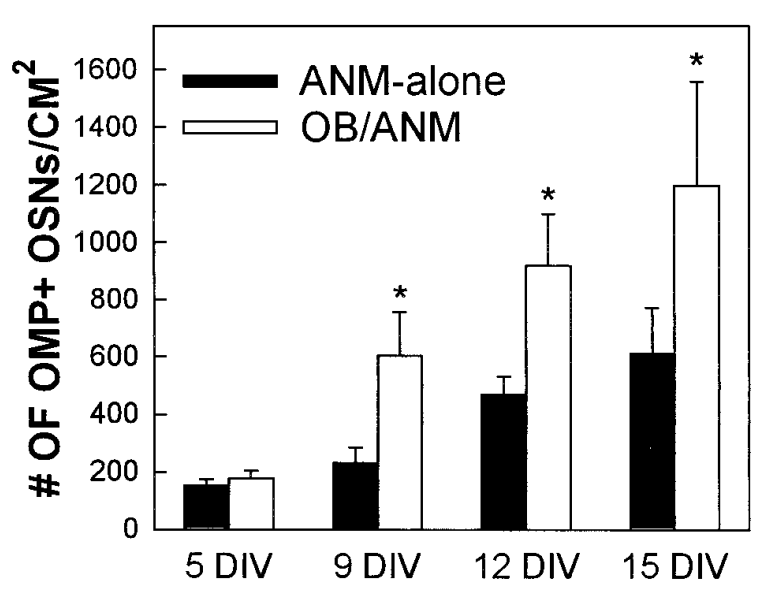

Figure 4. Coculture of ANM with dissociated OB cells resulted in increased numbers of OMP+ OSNs. OB/ANM cocultures showed a statistically significant increase in numbers of OMP+ OSNs at 9,12 , and 15 DIV, compared with ANM-alone, using a random effects GLS regression model ( $p<0.05$; analyses utilized the entire data set shown in Fig. 5). Error bars represent mean \pm SEM.

\section{Other CNS tissues also promoted OSN survival}

Data from in vitro explant culture studies suggest that the $\mathrm{OB}$ was unique in providing trophic support to OSNs, because other CNS and nonCNS tissues did not provide support (Chuah and Farbman, 1983). To investigate the trophic support specificity in our system, ANM cells were added to cultures containing newborn rat cerebellar cells (CERE/ANM), E-16 ventral mesencephalic cells (VM/ANM), and E-16 cerebral cortical cells (CORT/ANM). The times chosen for each CNS region dissection coincided with active neurogenesis in each region because this promotes optimal neuronal survival in culture.

At $5 \mathrm{DIV}$, there were no significant differences in numbers of OMP+ OSNs between ANM-alone and ANM cocultured with cells from any other CNS region (Fig. 5). At $9 \mathrm{DIV}$, in addition to OB/AMN (described above), CERE/ANM and VM/ANM cocultures contained greater numbers of OMP+ OSNs compared to ANM-alone (2.6- and 3.6-fold, respectively; Fig. 5). CORT/ANM cultures did not demonstrate any significant difference in OMP+ OSNs compared with ANM-alone at any time point. At $12 \mathrm{DIV}$, only $\mathrm{VM} / \mathrm{ANM}$ and $\mathrm{OB} / \mathrm{ANM}$ cocultures contained significantly greater numbers of OMP+ OSNs compared with ANM-alone (Fig. 5), with VM/ANM cocultures showing a 2.5-fold increase in numbers of OMP+ OSNs over ANM-alone.

By 15 DIV, OB/ANM and VM/ANM cocultures exhibited a significant increase in numbers of OMP+ OSNs (both about twofold) compared with ANM-alone (Fig. 5). Numbers of OMP+ OSNs in CERE/ANM and CORT/ANM cocultures at 15 DIV were not significantly different from ANM-alone (Fig. 5).

These results suggest that OSN survival requirements are not uniquely satisfied by the OB. Rather, coculture with three separate CNS tissues, the $\mathrm{OB}$, ventral mesencephalon, and cerebellum, can increase numbers of mature OSNs in vitro, compared with ANM cells alone.

\section{OSN survival requires CNS neurons}

Previous studies have demonstrated that the presence of a purified glial support layer increases the survival and/or differentiation of cultured newborn rat OSNs (Chuah et al., 1991; Trombley and Westbrook, 1991; Pixley, 1992a; Chuah and Au, 1994). In the cocultures just described, the CNS cells added included both neurons and glia. To test the relative contributions of neurons and glia to the support of OSN survival, partially purified glial cell populations with minimal neuronal contamination were substituted for the CNS cells and cocultured with ANM cells. Newborn cortical $(2 \mathrm{XCX})$ or OB glia (OBGLIA) were added to cortical glial feeder layers and then seeded with ANM cells. Neither cortical nor OB glia significantly altered numbers of OMP+ OSNs compared to ANM-alone cultures (Fig. 6) at either 9 or 12 DIV (the only time points tested). These results suggest that the trophic support provided by the OB, CERE, and VM was a result of the presence of neurons and not just glia.

\section{OSN survival and the presence of dopamine-secreting neurons}

The VM and OB resemble each other, and differ from the other tissues tested, in that both contain cells that synthesize dopamine. In the $\mathrm{OB}$, a subset of periglomerular interneurons secrete dopamine and express tyrosine hydroxylase $(\mathrm{TH})$ (the rate-limiting enzyme in dopamine synthesis; Baker, 1988). In the VM dissection, the tissues taken included the developing substantia nigra, which contains TH-immunoreactive neurons (Konig et al., 1989). Recent results demonstrating dopamine receptors on OSNs has lead to the hypothesis that dopamine mediates presynaptic contact between OSN axons and $\mathrm{TH}+$ neurons in the OB (Nickell et al., 1991). Dopamine may have other effects on OSNs, including trophic effects, because many neurotransmitters can affect neuronal survival and differentiation (Schwartz, 1992). Therefore, we asked whether numbers of dopaminergic neurons (measured by $\mathrm{TH}$ staining) matched increases in $\mathrm{OMP}+$ neurons in the cocultures. $\mathrm{TH}+$ cells were present only in $\mathrm{OB} / \mathrm{ANM}$, OB-alone, VM/ ANM, and VM-alone cultures (data not shown), and in all cultures their numbers were highest at 5 DIV. However, total cell numbers $\left(<200\right.$ cells $\left./ \mathrm{cm}^{2}\right)$ were low compared to OMP + neurons and highly variable across experiments. After $5 \mathrm{DIV}$, the numbers of $\mathrm{TH}+$ neurons decreased in all cultures so that by 12 DIV the numbers were very low, variable, and not significantly different between cocultures and single cultures. The low numbers of TH+ neurons and the time course differences from OMP+ numbers suggest that release of dopamine or another trophic factor by neurons actively synthesizing high levels of dopamine is not the only factor influencing OMP+ neurons.

In $\mathrm{VM} / \mathrm{ANM}$ cultures at $5 \mathrm{DIV}$, the numbers of $\mathrm{TH}+$ cells $(197 \pm 37$, mean \pm SEM, $n=7$ experiments) were significantly higher than in VM-alone cultures $(159 \pm 29, n=7, t$ test, $p<$ $0.05)$. Although a similar trend was seen in OB/ANM cocultures $(81 \pm 30, n=7)$ compared to OB-alone $(40 \pm 11, n=7)$, the differences were not significant $(t$ test $)$. These data suggest that coculture with ANM cells supported either increased survival of $\mathrm{VM}$ and $\mathrm{OB}$ dopamine neurons or continued expression of dopamine in these neurons.

\section{Rat skin fibroblasts did not support OSN survival}

Fibroblasts, which are abundant in the lamina propria underneath the olfactory epithelium, could provide neurotrophic support (Hansson et al., 1991). To test the effects of fibroblasts and to also test the trophic support of a tissue unrelated to the brain or nose, fibroblasts (FIBRO) were purified from newborn rat belly skin, cocultured with ANM cells on a cortical glia feeder layer (FIBRO/ ANM), and OMP + numbers were counted at 9 and 12 DIV (Fig. 7). At $9 \mathrm{DIV}$, there were no significant differences between ANM-alone and FIBRO/ANM cocultures. At 12 DIV, FIBRO/ ANM cocultures contained significantly fewer OMP+ OSNs than 


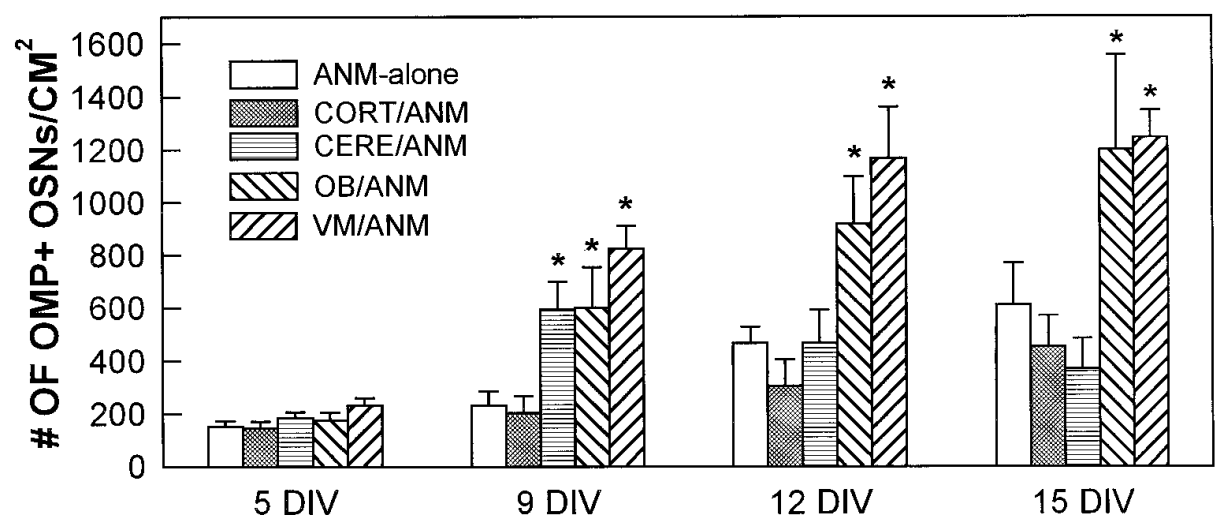

Figure 5. Coculture with nontarget CNS increased numbers of OMP+ OSNs. Numbers of OMP+ cells were compared between ANM-alone cultures and ANM cells cocultured with cells from the olfactory bulb, cerebellum, cerebral cortex, or ventral mesencephalon. VM/ANM cocultures demonstrated statistically greater OMP + OSN survival at 9,12, and 15 DIV compared with ANM-alone cultures at the same time points (random effects GLS regression model; ${ }^{*} p<0.05$ ). At 9 DIV, CERE/ANM cocultures contained greater numbers of OMP+ OSNs compared with ANM-alone (random effects GLS regression model; $\left.{ }^{*} p<0.05\right)$. At no time did CORT/ANM cocultures contain greater numbers of OMP+ OSNs compared with ANM-alone. Error bars represent mean \pm SEM.

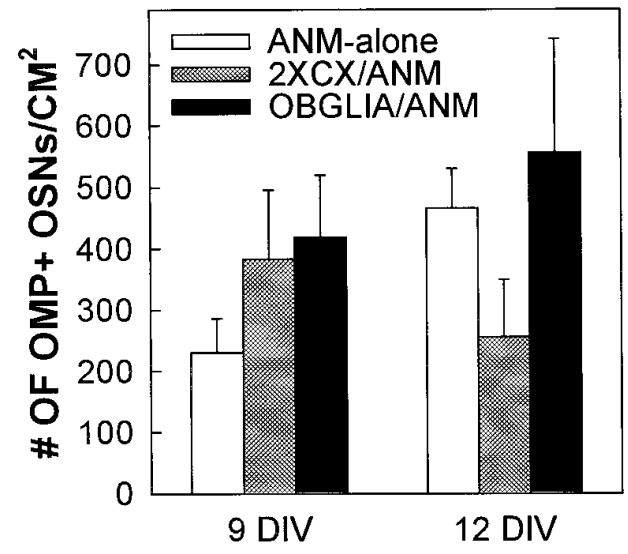

Figure 6. Addition of CNS glia did not enhance OMP+ OSN survival. Cocultures with added OB $(O B G L I A)$ or cortical glia $(2 X C X)$ did not contain significantly higher numbers of OMP+ OSNs at either 9 or 12 DIV compared with ANM-alone (one-way ANOVA; $p<0.05$ ). Error bars represent mean \pm SEM.

did ANM-alone cultures. These results suggest that coculture with fibroblasts, a non-CNS tissue, actually impairs OSN survival.

\section{DISCUSSION}

\section{Neurogenesis in ANM cultures}

Cultures derived from adult rat nasal tissues supported generation and differentiation of all OSNs and in particular, mature, OMP+ OSNs. As in newborn rat cultures (Pixley, 1992a), this occurred only if the nasal cells were plated on live, predominantly astrocytic, glial cultures. This demonstration of neurogenesis in vitro, using adult tissues, is novel and important given the limited capacity for neurogenesis in the majority of the adult nervous system.

The astrocytic feeder layer support seemed to be unique to this glial cell type because the dissociated ANM cell preparation (which did not survive by itself) contained abundant numbers of olfactory glia (also termed olfactory ensheathing cells), which share similarities with both Schwann cells and astrocytes (Doucette, 1990; Pixley, 1992b). This was also true in newborn rat cultures (Pixley, 1992a). A more rigorous test of glial specificity

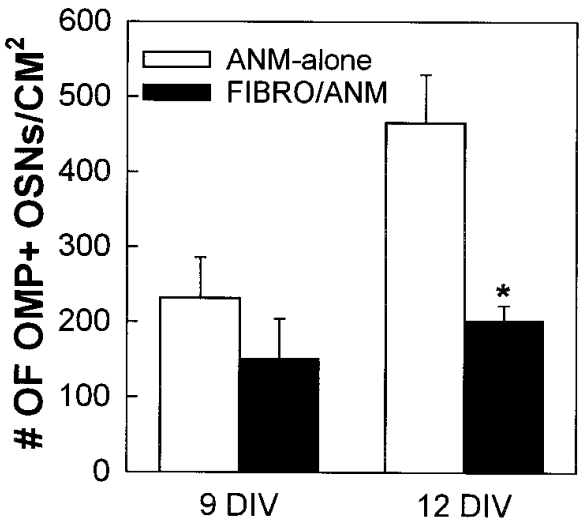

Figure 7. Skin fibroblasts did not enhance OMP+ OSN survival. Numbers of OMP + OSNs did not differ between ANM/FIBRO and ANMalone cultures at 9 DIV, whereas at 12 DIV, addition of fibroblasts caused a decrease in the numbers of OMP+ OSNs $\left(t\right.$ test; $\left.{ }^{*} p<0.05\right)$. Error bars represent mean \pm SEM.

currently under investigation is the development of monolayers of purified olfactory glial cells (and olfactory fibroblasts). In the intact animal, OSN axons contact CNS astrocytes only after they enter the OB. Thus, part of the OB-derived trophic support of OSNs (but not all, as shown here) may arise from contact with CNS astrocytes.

The timing of appearance of silver grain-labeled NST + and $\mathrm{OMP}+$ neurons after pulse labeling with $\left[{ }^{3} \mathrm{H}\right]$ thymidine suggests OSNs differentiate from an undetectable progenitor to NST+, immature neuron (labeled $3 \mathrm{~d}$ after pulse) to NST-, OMP+, mature neuron (labeling not detected until $6 \mathrm{~d}$ after the pulse). This timing resembles that observed in the intact animal (OMP expression is first seen $7 \mathrm{~d}$ after pulsing; Miragall and Monti Graziadei, 1982) and in newborn cell cultures ( $2 \mathrm{~d}$ to expression of NST, $4 \mathrm{~d}$ to expression of OMP; Pixley, 1992a).

\section{Differences between adult and newborn cultures}

Adult olfactory cell cultures differed from newborn cultures, first, in that adult cells did not survive to $24 \mathrm{hr}$ when plated on a polylysine-coated substrate, despite some cellular attachment. With newborn cells, OSNs plated on polylysine survived at least 7 
DIV (Pixley and Pun, 1990; Pixley, 1992a; Grill and Pixley, 1993). Thus, newborn neurons are more robust and/or have different substrate requirements than adult neurons. Second, the ratio of $\mathrm{OMP} / \mathrm{NST}+$ neurons at $1 \mathrm{DIV}$ in adult cultures was reversed from that in newborn rat cultures (Pixley, 1992a). This reflects developmental differences in the intact tissues (Lee and Pixley, 1994). Third, the loss of OMP+ neurons at 5 DIV was more complete in newborn than in adult cultures. This probably reflects the greater numbers of OMP+ OSNs entering the adult cultures; an equal loss was more complete in the adult cultures.

A fourth difference was that adult cultures could not be maintained past 15 DIV, whereas newborn cultures were readily maintained to 20 DIV without signs of degeneration (Pixley, 1992a). The adult cultures demonstrated a variable instability, with loss of the entire cell mat in some, but not all, wells. Similar instabilities were observed in the OB/ANM and VM/ANM cultures, but never in cultures without ANM cells. Because the cultures always seemed healthy, this may be a result of overgrowth of nonneuronal cells, possibly stimulated by ANM-derived trophic factors.

Finally, the maximal numbers of OMP + OSNs reached in adult cultures at 12 DIV (919 OMP + neurons $/ \mathrm{cm}^{2}$ ) were significantly lower than in newborn cultures at 15 DIV (around 3,000 OMP+ neurons $/ \mathrm{cm}^{2}$; Pixley, 1992a). This is unusual because the numbers of OMP + neurons at 1 DIV were much higher in adult cultures. This may reflect the fact that neuronal aggregation was more extensive in newborn cultures. There, almost all neurons were tightly packed in micro-noses by 15 DIV (Pixley et al., 1994). In adult cultures, neurons occurred mostly in loose clusters, whereas the few clusters exhibiting micro-nose organization were smaller and less compact. This may reflect or result from differences in autocrine or paracrine trophic factors. Alternatively, adult OSNs may have different responses to growth factors.

One similarity between adult and newborn cultures was that the timing of the disappearance and "return" of OMP + neurons was similar and resembled changes in the intact olfactory epithelium after a bulbectomy or nerve section. In both cultures, OMP+ OSNs disappeared at 1-5 DIV, and the return occurred around 12 DIV in adult and 10 DIV in newborn cultures (Pixley, 1992a). After experimental damage in vivo, OMP+ OSNs disappear by $\sim 4-6 \mathrm{~d}$ and are detectable again by $8-12 \mathrm{~d}$ after injury (Graziadei and Graziadei, 1979; Samanen and Forbes, 1984; Schwob et al., 1992). Thus, cultures from either adult or newborn rat tissues are good models of events in the intact animal after experimental manipulations.

\section{OB/ANM cocultures: OSN dependence on the OB for trophic support}

As discussed previously, several lines of evidence support the hypothesis that contact with the OB provides trophic support that increases survival and prevents early apoptotic death of immature OSNs. This then allows OSNs to complete maturation, which is assumed at present to include formation of mature cilia and expression of OMP. This hypothesis is supported by previous explant culture studies. Olfactory epithelial explants cocultured with OB explants (for $10 \mathrm{DIV}$ ) display twofold increases in OMP protein content and OMP+ numbers over epithelial explants cultured alone (Chuah and Farbman, 1983; Chuah et al., 1985). This effect required physical contact between the two types of explant (Chuah and Farbman, 1983). It was of interest that our observed increase in numbers of OMP+ OSNs at 12 DIV and longer in cocultures compared to single cultures were also roughly twofold, perhaps suggesting a limited amount of, or a limited response to, the OB-derived trophic support. In terms of physical contact, we have no definitive data yet, but OB neurons were detected within the loose clusters of OSNs where they could physically contact OSNs (Grill and Pixley, unpublished results).

\section{ANM/nontarget cocultures: specificity of trophic support}

In the previous explant studies, coculturing epithelial explants with explants from the cerebrum, cerebellum, cervical spinal cord, and heart did not increase numbers of OMP+ neurons in the epithelial explants (Chuah and Farbman, 1983). We similarly saw no increases with cerebral tissues or a non-neural control, skin fibroblasts. However, we observed a transient increase with cerebellar cells. This difference could be because of the age of the tissue taken [newborn in our study vs embryonic (E-15) in the explant study]. With OB explant cultures, the trophic support varies with the developmental age of the tissue (Chuah and $\mathrm{Au}$, 1988). Our results thus suggest that the P-1 but not E-15 cerebellum provides some trophic support to adult OSNs in vitro. Finally, our study showed trophic support by ventral mesencephalic cells, which were not tested in the explant studies. Overall, both the explant studies and this study show significant differences between CNS regions in their trophic support of OSNs. Our studies broaden the scope of tissues examined and provide information for future comparative studies aimed at isolation and characterization of growth factors.

\section{Tyrosine hydroxylase expression was not temporally correlated with OMP expression}

Because $\mathrm{TH}+$ neurons were scarce in cocultures with $\mathrm{OB}$ or VM cells and their appearance did not coincide with appearance of $\mathrm{OMP}+$ neurons, this particular class of cells does not seem to provide trophic support for OSNs. However, other explanations have not been explored, i.e., $\mathrm{TH}+$ neurons, before their loss, may affect early stages in the OSN lineage. Future studies will examine influences of $\mathrm{TH}+$ neurons on early OSN development, as well as the trophic support provided by other subsets of OB neurons.

\section{ANM cocultures: effects of non-neuronal cell types}

The dissociated CNS cells that supported increased OMP+ OSNs contained astrocytes, oligodendrocytes, microglia, and fibroblasts, in addition to neurons. Whereas fibroblasts can provide trophic support, i.e., to keratinocytes (Limat et al., 1989), skin fibroblasts were not supportive in this assay. Both astrocytes and microglia are more likely candidates for producing OSN trophic factors because they produce numerous neurotrophic factors in vivo and in vitro (Muller et al., 1995). However, we directly compared purified $\mathrm{OB}$ glia (which contain astrocytes and some microglia) with mixed OB cells (both from newborn rats) and did not see increased numbers of OMP+ OSNs. Oligodendrocytes have rarely been shown to be neurotrophic. Thus, our results suggest, but do not prove, that neurons, which are a major component of these cell mixtures, were the source of the trophic support for OSNs.

\section{Summary}

Adult rat nasal cell cultures supported in vitro survival, generation, and maturation of OSNs, including production of OMP+ neurons. An important requirement was the use of a supportive bed layer of cortical glia. Evidence of target-derived trophic support was demonstrated by coculturing ANM cells with OB cells, but trophic support was also variably provided by nontarget 
CNS tissues. The source of trophic support seemed to be neurons. This novel culture system can now be used for further characterization of the target- and nontarget-derived neurotrophic support.

\section{REFERENCES}

Baker H (1988) Neurotransmitter plasticity in the juxtaglomerular cells of the olfactory bulb. In: Molecular neurobiology of the olfactory system (Margolis FL, Getchell TV, eds), pp 185-216. New York: Plenum.

Barber PC, Jensen S (1988) Olfactory tissue interaction studied by intraocular transplantation. In: Molecular neurobiology of the olfactory system (Margolis FL, Getchell TV, eds), pp 185-216. New York: Plenum.

Calof AL, Chikaraishi DM (1989) Analysis of neurogenesis in a mammalian neuroepithelium: proliferation and differentiation of an olfactory neuron precursor in vitro. Neuron 3:115-127.

Carr VM, Farbman AI (1992) Ablation of the olfactory bulb up-regulates the rate of neurogenesis and induces precocious cell death in olfactory epithelium. Exp Neurol 115:55-59.

Carr VM, Farbman AI (1993) The dynamics of cell death in the olfactory epithelium. Exp Neurol 124:308-314.

Chuah MI, Au C (1988) Number of olfactory marker protein-containing receptor cells is influenced by developmental stage of the olfactory bulb. J Neurosci Res 20:84-89.

Chuah MI, Au C (1994) Olfactory cell cultures on ensheathing cell monolayers. Chem Senses 19:25-34.

Chuah MI, Farbman AI (1983) Olfactory bulb increases marker protein in olfactory receptor cells. J Neurosci 3:2197-2205.

Chuah MI, Farbman AI, Menco B (1985) Influence of olfactory bulb on dendritic knob density of rat olfactory receptor neurons in vitro. Brain Res 338:259-266.

Chuah MI, David S, Blaschuk O (1991) Differentiation and survival of rat olfactory epithelial neurons in dissociated cell culture. Dev Brain Res 60:123-132.

Costanzo RM (1984) Comparison of neurogenesis and cell replacement in the hamster olfactory system with and without a target (olfactory bulb). Brain Res 307:295-301.

Costanzo RM, Graziadei PPC (1983) A quantitative analysis of changes in the olfactory epithelium following bulbectomy in hamster. J Comp Neurol 215:370-381.

Doucette R (1990) Glial influences on axonal growth in the primary olfactory system. Glia 3:433-449.

Farbman AI (1992) Cell biology of olfaction. New York: Cambridge University.

Farbman AI, Buchholz JA (1992) Growth of olfactory epithelial tissue in vitro: lectin staining of axons. Microsc Res Tech 23:173-180.

Farbman AI, Margolis FL (1980) Olfactory marker protein during ontogeny: immunohistochemical localization. Dev Biol 74:205-215.

Graziadei GA, Graziadei PPC (1979) Neurogenesis and neuron regeneration in the olfactory system of mammals. II. Degeneration and reconstitution of the olfactory sensory neurons after axotomy. J Neurocytol 8:197-213.

Graziadei PPC, Monti Graziadei GA (1978a) The olfactory system: a model for the study of neurogenesis and axon regeneration in mammals. In: Neuronal plasticity (Cotman CW, ed), pp 131-153. New York: Raven.

Graziadei PPC, Monti Graziadei GA (1978b) Continuous nerve cell renewal in the olfactory system. In: Handbook of Sensory Physiology (Jacobson, M, ed.), pp. 55-84. New York: Springer.

Graziadei PPC, Monti Graziadei GA (1979) Neurogenesis and neuron regeneration in the olfactory system of mammals. I. Morphological aspects of differentiation and structural organization of the olfactory sensory neurons. J Neurocytol 8:1-18.

Graziadei PPC, Stanley RS, Monti Graziadei GA (1980) The olfactory marker protein in the olfactory system of the mouse during development. J Neurosci 5:1239-1252.

Grill RJ, Pixley SK (1993) 2-Mercaptoethanol is a survival factor for olfactory, cortical and hippocampal neurons in short term dissociated cell culture. Brain Res 613:168-172.

Hansson HA, Jorgensen F, Petruson B, Petruson K (1991) Regenerating human nasal mucosal cells express peptide growth factors. Arch Otolaryngol Head Neck Surg 117:1368-1377.
Harding JW, Graziadei PPC, Monti Graziadei GA, Margolis FL (1977) Denervation in the primary olfactory pathway of mice. IV. Biochemical and morphological evidence for neuronal replacement following nerve section. Brain Res 132:11-28.

Harlow E, Lane D (1988) Cell staining. In: Antibodies. A laboratory manual (Harlow E, Lane D, eds), pp 418. Cold Spring Harbor, NY: Cold Spring Harbor Laboratory.

Hinds JW, Hinds PL (1976) Synapse formation in the mouse olfactory bulb. I. Quantitative studies. J Comp Neurol 169:15-40.

Konig N, Wilkie MB, Lauder J (1989) Dissection of monoaminergic neuronal groups from embryonic rat brain. In: A dissection and tissue culture manual of the nervous system (Shahar A, de Vellis J, Vernadakis A, Haber B, eds), pp 26-29. New York: Liss.

Lee V, Pixley SK (1994) Age-related differences in neuron-specific tubulin immunostaining of olfactory receptor neurons. Dev Brain Res 83:209-215.

Levison SW, McCarthy KD (1991) Astroglia in culture. In: Culturing nerve cells (Banker G, Goslin K, eds), pp 309-336. Cambridge: MIT.

Limat A, Hunziker T, Boillat C, Bayreuther K, Noser F (1989) Postmitotic human dermal fibroblasts efficiently support the growth of human follicular keratinocytes. J Invest Dermatol 92:758-762.

Miragall F, Monti Graziadei GA (1982) Experimental studies on the olfactory marker protein. II. Appearance of the olfactory marker protein during differentiation of the olfactory sensory neurons of mouse: an immunohistochemical and autoradiographic study. Brain Res 329:245-250.

Monti Graziadei GA, Graziadei PPC (1979) Neurogenesis and neuron regeneration in the olfactory system of mammals. II. Degeneration and reconstitution of the olfactory sensory neurons after axotomy. J Neurocytol 8:197-213.

Muller H, Junghans U, Kappler J (1995) Astroglial neurotrophic and neurite-promoting factors. Pharmacol Ther 65:1-18.

Nickell WT, Norman AB, Wyatt LM, Shipley MT (1991) Olfactory bulb DA receptors may be located on terminals of the olfactory nerve. NeuroReport 2:9-12.

Pixley SK (1992a) CNS glial cells support in vitro survival, division, and differentiation of dissociated olfactory neuronal progenitor cells. Neuron 8:1191-1204.

Pixley SK (1992b) The olfactory nerve contains two populations of glia, identified both in vivo and in vitro. Glia 5:269-284.

Pixley SK (1992c) Purified cultures of keratin-positive olfactory epithelial cells: identification of a subset as neuronal supporting (sustentacular) cells. J Neurosci Res 31:693-707.

Pixley SK (1996) Characterization of olfactory receptor neurons and other cell types in dissociated rat olfactory cell cultures. Int J Dev Neurosci, in press.

Pixley SK, Pun RYK (1990) Cultured rat olfactory neurons are excitable and respond to odors. Dev Brain Res 53:125-130.

Pixley SK, Bage M, Miller D, Miller ML, Shi M, Hastings L (1994) Olfactory neurons in vitro show phenotypic orientation in epithelial spheres. NeuroReport 5:543-548.

Ronnett GV, Hester LD, Snyder SH (1991) Primary cultures of neonatal rat olfactory neurons. J Neurosci 11:1243-1255.

Samanen DW, Forbes WB (1984) Replication and differentiation of olfactory receptor neurons following axotomy the adult hamster: a morphometric analysis of post-natal neurogenesis. J Comp Neurol 225:201-211.

Schwartz JP (1992) Neurotransmitters as neurotrophic factors: a new set of functions. Int Rev Neurobiol 34:1-23.

Schwob JE, Szumowski KEM, Stasky AA (1992) Olfactory sensory neurons are trophically dependent of the olfactory bulb for their prolonged survival. J Neurosci 12:3896-3919.

Trombley PQ, Westbrook GL (1991) Voltage-gated currents in identified rat olfactory receptor neurons. J Neurosci 11:435-444.

Verhaagen J, Greer CA, Margolis FL (1990) B-50/GAP43 gene expression in the rat olfactory system during postnatal development and aging. Eur J Neurosci 2:397-407.

Verhaagen J, Oestreicher AB, Gispen WH, Margolis FL (1989) The expression of the growth associated protein B50/GAP43 in the olfactory system of neonatal and adult rats. J Neurosci 9:683-691. 